\title{
Changes in airway resistance induced by nasal or oral intermittent positive pressure ventilation in normal individuals
}

\author{
P. Fontanari, H. Burnet, M.C. Zattara-Hartmann, M. Badier, Y. Jammes
}

\begin{abstract}
Changes in airway resistance induced by nasal or oral intermittent positive pressure ventilation in normal individuals. P. Fontanari, H. Burnet, M.C. Zattara-Hartmann, M. Badier, Y. Jammes. (C)ERS Journals Ltd 1999.

ABSTRACT: Nasal intermittent positive-pressure ventilation (nIPPV) is used for the treatment of respiratory failure in patients with neuromuscular disease. The aim of the present study was to demonstrate that nIPPV may activate nose receptors, the consequence of which being reflex changes in lung resistance.

The changes in interrupter resistances (Rint) in response to nIPPV were tested before and after local anaesthesia of the nasal mucosa in normal subjects. They were compared to the $R$ int changes induced by oral intermittent positive-pressure ventilation (OIPPV) in the same individuals. Rint was measured during 10-min periods of nIPPV or oIPPV at a constant rate $\left(15 \mathrm{~L} \cdot \mathrm{min}^{-1}\right)$, but at two different stroke volumes $(0.8$ and $1.2 \mathrm{~L})$. Inspired temperature and relative humidity were held constant.

nIPPV with $1.2 \mathrm{~L}\left(17 \mathrm{~mL} \cdot \mathrm{kg}^{-1}\right)$ significantly increased the $R$ int value $(+22 \%)$. This effect disappeared after nose anaesthesia or after inhalation of a cholinergic antagonist. oIPPV never changed $R$ int, even though the associated hypocapnia was present and more accentuated than during nIPPV. Adding $\mathrm{CO}_{2}$ to the inspired gas during nIPPV and oIPPV trials suppressed the Rint changes.

The present study suggests the existence of a nasopulmonary bronchoconstrictor reflex elicited through the stimulation of nasal mechanoreceptors, their activity being markedly influenced by the changes in expired $\mathrm{CO}_{2}$ concentration.

Eur Respir J 1999; 13: 867-872.
\end{abstract}

Laboratoire de Physiopathologie Respiratoire EA2201, Institut Jean Roche, Faculté de Médecine, Université de la Méditerrannée, Marseille, France.

Correspondence: Y. Jammes, Laboratoire de Physiopathologie Respiratoire EA2201, Faculté de Médecine, Bd. Pierre Dramard, 13916 Marseille cedex 20, France, Fax: 33 491698927

Keywords: Bronchomotor control

cold receptors

flow receptors

human

nasal intermittent positive pressure ventilation

nose

Received: February 261998

Accepted after revision October 121998

Supported by grants from AFM (Association Française de lutte contre les Myopathies) and Institut Garches.
Studies in monkeys, dogs, cats and rats suggest the existence of mechanoreceptors and more specifically flow receptors in the nasal mucosa [1-5]. They are activated by direct contact with the nasal mucosa (nylon fibre, gauze packing) and also by an increase in the air flow rate or pressure through the nasal cavity. Some studies in animals $[3,5]$ and humans $[6,7]$ have demonstrated the existence of thermoreceptors, namely cold-receptors, in the nose. The afferent fibres connected to mechano- or thermosensitive nasal endings are found in the trigeminal nerve. Their activation elicites bronchomotor responses. In healthy subjects [6], and mainly in patients with bronchial hyperreactivity [7], the nasal inhalation of cold air induces a reflex increase in airway resistance (Raw). This acts as a protective mechanism that limits the entry of cold air into the lower airways. However, data in the literature on the bronchomotor effects of the mechanical nasal stimulation are less uniform. A nasopulmonary bronchoconstrictor reflex in response to nasal irritation had already been described in humans by KAUFMAN and coworkers [8,9]. These studies showed the existence of a reflex originating in the nose, transmitted by the trigeminal nerve (afferent pathway) and terminating, via the vagus nerve (efferent pathway), in the bronchi. IsHIZUKA and Usui [10] showed in normal subjects that mechanical nasal stimulation by insertion of a sheet of gauze induced an immediate increase in Raw in some individuals, whereas it lowered the baseline Raw value in others. By contrast, TOMORI and WidDICOMBE [2] reported a bronchodilator response to mechanical stimulation of the nasal mucosa with a thin nylon fibre in cats. However, the effect adapted rapidly, with the bronchomotor response decreasing in magnitude during the 20 -s period of mechanical stimulation.

Mechanical ventilation through a nasal mask (nasal intermittent positive-pressure ventilation (nIPPV)) is used for treatment of respiratory failure in patients with neuromuscular disease [11]. STrohl and Redine [12] showed that positive pressure applied to the nose opens the upper airways and prevents obstructive apnoea. However, few studies were conducted to analyse the possible effects of nIPPV on nasal mechanosensitive units and the consecutive nasopulmonary reflexes. In the literature two recent works were found by JounIEAuX et al. $[13,14]$ in normal awake and sleeping subjects, who reported that nIPPV resulted in vocal cord adduction. However, the authors mostly attributed the upper airway response to a direct effect of hypocapnia and not to a reflex initiated by the activation of nose receptors.

The aim of the present study, conducted during eupnoeic nasal ventilation in normal subjects, was to analyse the changes in interrupter resistance (Rint) in response to nIPPV. In order to test the hypothesis that nIPPV may elicite nasopulmonary reflexes, tests were repeated after anaesthesia of the nasal mucosa and also during intermittent positive-pressure breathing through the mouth (oral intermittent positive-pressure ventilation (oIPPV)), a 
condition that bypassed nose receptors. The evidence of a bronchomotor response and not a laryngeal response to nIPPV, was given by the suppression of Rint changes after oral inhalation of a cholinergic antagonist.

\section{Methods}

\section{Subjects}

Twelve healthy subjects (five females) volunteered to participate in the present study. Their mean \pm SD age was $36 \pm 10$ yrs. None had any antecedents or symptoms of asthma and rhinitis. Table 1 shows that their pulmonary function was normal and they had no airway hyperreactivity to carbachol. A dose-response curve was obtained for each individual by plotting the value of Raw, measured in a body pressure plethysmograph (Masterscreen Body; Erich Jaeger, Würzburg, Germany) by the method of DuBois et al. [15], against cumulative doses of carbachol in the range $200-1,800 \mu \mathrm{g}$. None of the subjects had a two-fold increase in Raw when the carbachol dose was $<1,200 \mu \mathrm{g}$, and in five subjects, no $R$ aw variation could be detected at the highest dose. As mandated by the Institutional Human Subjects Committee, the subjects were fully informed of all procedures, and written consent was obtained, but they remained naive as to the purpose of the study.

\section{Measurements of respiratory variables}

Measurements were always performed on subjects who were comfortably seated. In all cases, they inhaled room air via a two-way valve (dead space: $5 \mathrm{~mL}$ ), which avoided contamination of inspired air by expired gas. During nasal breathing, the subjects wore a mask (nasal continuous positive airway pressure mask (Respironics, Nantes, France), dead space $=140 \mathrm{~mL}$ ) firmly adjusted to the nose. During oral breathing, they were connected to a rigid mouth piece and wore a noseclip.

Interrupter system resistance. This method has already been used in spontaneously breathing subjects [16] as well as in anaesthetized and paralysed humans [17, 18]. Subjects breathed through a mouthpiece. The interrupter valve and a grid pneumotachograph, all of identical diameters $(24 \mathrm{~mm})$, were placed in series. Flow interruptions were performed with a computer-controlled motor driven throttle valve (Masterscreen; Erich Jaeger) that occluded the airway opening in $4 \mathrm{~ms}$. Mouth pressure was measured with a piezoelectric sensor (response time $=0.1 \mathrm{~ms}$ ). The total dead space was $25 \mathrm{~mL}$. A midexpiratory occlusion, lasting $100 \mathrm{~ms}$, was performed every second breath during a breathing period at a 15 breaths $\min ^{-1}$ frequency given by a metronome. As already described by PHAGOO et al. [16], the linearly backextrapolated occlusion pressure was computed from the post occlusion signal. The resistance of the grid pneumotachograph $\left(0.2 \mathrm{cmH}_{2} \mathrm{O} \cdot \mathrm{L}^{-1} \cdot \mathrm{s}\right)$ was subtracted. During the control condition (before each nIPPV or oIPPV trial), $R$ int was measured as the average of 10 separate expiratory occlusions. However, the Rint value measured when the subject was disconnected from the ventilator during nIPPV or oIPPV trials was the average of two successive occlusions. As clearly shown by PHAGOO et al. [16], the interrupter technique had a poorer sensitivity for detecting bronchoconstriction than the standard techniques that use an oesophageal balloon or a body plethysmograph. However, this technique was more convenient for measuring the airway response during periods of nIPPV and required minimal subject cooperation.

Gas temperature. Temperature was measured using a type $\mathrm{T}$ thermocouple $(67 \%$ response in $10 \mathrm{~ms}$; Bioblock Scientific, Strasbourg, France), inserted in the outlet of the circuit just before the two-way valve, allowing the expiratory gas to be separated from the inspired air.

Relative humidity. A thermohygrometer (time constant: 3 s) (Quick Novo; Bioblock Scientific) was placed in the inspiratory line of the circuit. Relative humidity $(\mathrm{RH})$ values were read on a digital voltmeter. In all cases, the inspired gas temperature and relative humidity remained stable during periods of spontaneous as well as mechanical ventilation (inspired temperature $=23 \pm 1^{\circ} \mathrm{C}$; $\mathrm{RH}=34 \pm 1 \%$ ).

Table 1. - Morphological characteristics, pulmonary function and airway response to carbachol inhalation of subjects

\begin{tabular}{lcccccccccc}
\hline $\begin{array}{l}\text { Subject } \\
\text { No. }\end{array}$ & Sex & $\begin{array}{c}\text { Age } \\
\text { yrs }\end{array}$ & $\begin{array}{c}\text { Weight } \\
\mathrm{kg}\end{array}$ & $\begin{array}{c}\text { Height } \\
\mathrm{cm}\end{array}$ & $\begin{array}{c}\text { VC } \\
\text { BTPS }\end{array}$ & $\begin{array}{c}\text { FEV1/VC } \\
\%\end{array}$ & $\begin{array}{c}\text { RV/TLC } \\
\%\end{array}$ & $\begin{array}{c}R \text { aw } \\
\mathrm{cmH}_{2} \mathrm{O} \cdot \mathrm{L}^{-1} \cdot \mathrm{s}^{-}\end{array}$ & $\begin{array}{c}\text { Rint } \\
\mathrm{cmH}_{2} \mathrm{O} \cdot \mathrm{L}^{-1} \cdot \mathrm{s}\end{array}$ & $\begin{array}{c}\text { Sensitivity to carbachol } \\
\mu \mathrm{g}\end{array}$ \\
\hline 1 & $\mathrm{M}$ & 50 & 62 & 167 & 3.97 & 97 & 43 & 1.58 & 1.82 & $>1800$ \\
2 & $\mathrm{M}$ & 23 & 72 & 176 & 5.62 & 111 & 15 & 2.32 & 2.48 & $>1800$ \\
3 & $\mathrm{M}$ & 46 & 89 & 182 & 5.70 & 108 & 26 & 1.03 & 1.97 & $>1200$ \\
4 & $\mathrm{M}$ & 31 & 63 & 173 & 5.48 & 92 & 33 & 2.24 & 3.32 & $>1800$ \\
5 & $\mathrm{M}$ & 55 & 95 & 172 & 4.30 & 82 & 31 & 2.05 & 1.85 & $>1800$ \\
6 & $\mathrm{M}$ & 26 & 75 & 171 & 5.51 & 76 & 33 & 2.10 & 3.16 & $>1800$ \\
7 & $\mathrm{M}$ & 26 & 77 & 170 & 4.91 & 84 & 25 & 2.10 & 2.57 & $>1800$ \\
8 & $\mathrm{~F}$ & 44 & 51 & 157 & 3.34 & 80 & 26 & 2.39 & 3.22 & $>1800$ \\
9 & $\mathrm{~F}$ & 29 & 57 & 170 & 4.96 & 85 & 25 & 2.50 & 2.64 & $>1800$ \\
10 & $\mathrm{~F}$ & 37 & 73 & 176 & 4.17 & 90 & 24 & 2.33 & 2.40 & $>1800$ \\
11 & $\mathrm{~F}$ & 32 & 49 & 158 & 3.02 & 80 & 26 & 1.60 & 2.89 & $>1800$ \\
12 & $\mathrm{~F}$ & 37 & 52 & 156 & 3.85 & 82 & 33 & 2.53 & 3.10 & \\
\hline
\end{tabular}

M: male; F: female; VC: vital capacity; FEV1: forced expiratory volume in one second; RV: residual volume; TLC: total lung capacity; Raw: central airway resistance (plethysmographic measurement); Rint: interrupter resistance; sensitivity to carbachol: dose doubling baseline Raw value. 
Inlet pressure. Inlet pressure was measured from a port in the nasal mask or in the mouthpiece with an electromanometer $\left( \pm 20 \mathrm{cmH}_{2} \mathrm{O}\right.$, Schlumberger, Velizy, France) calibrated with an alcohol-filled manometer.

Changes in thoracic and abdominal volumes. A Respitrace (Ambulatory Monitoring, New York, USA) calibrated with the isovolume technique was used to measure ribcage and abdomen volume changes in response to nIPPV and oIPPV.

End-tidal carbon dioxide fraction. A rapid infra-red $\mathrm{CO}_{2}$ analyser (Capnograph, Godart, Amsterdam, The Netherlands) measured the expired carbon dioxide fraction $\left(F \mathrm{E}, \mathrm{CO}_{2}\right)$ during mechanical ventilation. Only endtidal carbon dioxide fraction $\left(F \mathrm{ET}, \mathrm{CO}_{2}\right)$ values were considered. Output signals of Respitrace, $\mathrm{FE}, \mathrm{CO}_{2}$ and nose (or mouth) pressure were simultaneously recorded on a polygraph (ES1000, Gould, Ballainviliers, France).

Mechanical ventilation. This was delivered by a volume respirator through the nasal mask or the mouthpiece. An Eole 2NA (Saime Electronique, Savigny le Temple, France) was used. The respirator frequency was fixed at 15 breaths $\mathrm{min}^{-1}$, but the delivered tidal volume was started randomly at either 0.8 or $1.2 \mathrm{~L}(11$ and $17 \mathrm{~mL}$. $\mathrm{kg}^{-1}$, respectively). nIPPV and oIPPV were delivered for 10-min periods, during which Rint measurements were performed at $2.5,5$ and $10 \mathrm{~min}$. A 10 - min period of spontaneous room air breathing separated two consecutive periods of mechanical ventilation. Rint was measured again at the end of the 10-min period, and this constituted the control value for the second nIPPV or oIPPV trial. During nIPPV and oIPPV the subjects were disconnected from the ventilator and breathed through the device used to measure Rint. Only two consecutive $R$ int values were averaged. Indeed, during the setting of the final protocol, it was observed that nIPPV induced $R$ int changes persisted only for $\sim 20 \mathrm{~s}$ after the ventilator had been disconnected. In five individuals (subjects 1-4 and subject 8), mechanical ventilation was also performed during periods during which $F \mathrm{ET}, \mathrm{CO}_{2}$ was maintained constant by adding pure $\mathrm{CO}_{2}$ to the admission filter of the respirator to increase $F \mathrm{ET}, \mathrm{CO}_{2}$ without changing the delivered ventilation.

Local anaesthesia of the nasal mucosa. In four subjects (1-3 and 7), the consequences of nIPPV with a $1.2 \mathrm{~L}$ tidal volume on $R$ int were studied before and after local anaesthesia of the nasal mucosa using nebulization plus instillation of $1 \mathrm{~mL}$ of a $5 \%$ xylocaine solution. Baseline $R$ int values were measured 5 min after anaesthesia, and then the nIPPV trial begun immediately. No adjustment of $F \mathrm{ET}, \mathrm{CO}_{2}$ value was performed.

Oral inhalation of a cholinergic antagonist. In six subjects (1-3, 5, 6 and 10) nIPPV challenges with 1.2 L tidal volume were repeated $30 \mathrm{~min}$ after oral inhalation of a cholinergic antagonist ( $40 \mu \mathrm{g}$ of ipratropium bromide; Atrovent, Boehringer Ingelheim, Paris, France). As JouniEAUX et al. [13] considered that nIPPV induced glottis narrowing, this method was used to determine whether or not laryngeal constriction participated in the nIPPV induced changes in Rint.

Statistical analysis. After assessment of data normality (Kolmogorov-Smirnov test), a one-way repeated-measures analysis of variance was used, which allowed us to test for differences in the effects of a series of experimental conditions on the same group of subjects, by examining the changes in each individual. To determine whether Rint values measured during periods of nasal or oral positive pressure breathing differed significantly from the corresponding control values measured during the room air breathing periods preceding the tests, Dunnett's method was used, as a post-ANOVA multiple comparison test, when ANOVA indicated the existence of a significant difference $(\mathrm{p}<0.05)$ within these experimental conditions.

\section{Results}

Changes in amplitude of breaths, end-expiratory volumes and $\mathrm{FET}, \mathrm{CO}_{2}$ during mechanical ventilation

Table 2 shows the mean values of nasal and mouth inspiratory pressures, ribcage and abdominal tidal volumes and the changes in end-expiratory volumes given by the Respitrace just prior to measuring Rint. No significant variations were found. Thus, Rint measurements during nIPPV and oIPPV were always performed at a constant lung volume. $F$ ET, $\mathrm{CO}_{2}$ fell significantly during nIPPV, and this effect was proportional to the stroke volume (fig. 1). oIPPV accentuated the fall in $\mathrm{FET}, \mathrm{CO}_{2}$.

Table 2. - Changes in respiratory parameters during spontaneous ventilation

\begin{tabular}{|c|c|c|c|c|c|}
\hline & $\begin{array}{c}\mathrm{Pi}_{\mathrm{i}} \\
\mathrm{cmH}_{2} \mathrm{O}\end{array}$ & $\begin{array}{c}V_{\mathrm{rc}} \\
\mathrm{L}\end{array}$ & $\begin{array}{c}V \mathrm{ab} \\
\mathrm{L}\end{array}$ & $\underset{\%}{\Delta \mathrm{EEV} \text { rc }}$ & $\underset{\%}{\Delta \mathrm{EEV} V \mathrm{ab}}$ \\
\hline \multicolumn{6}{|l|}{ Nasal breathing } \\
\hline Control & $1.6 \pm 0.1$ & $0.71 \pm 0.10$ & $0.94 \pm 0.15$ & & \\
\hline nIPPV 0.8 L & $7.9 \pm 0.9$ & $0.75 \pm 0.05$ & $0.85 \pm 0.08$ & -0.7 & +4 \\
\hline nIPPV 1.2 L & $12.9 \pm 1.2$ & $1.06 \pm 0.08$ & $0.95 \pm 0.12$ & +1 & +3 \\
\hline \multicolumn{6}{|l|}{ Oral breathing } \\
\hline Control & $2.1 \pm 0.2$ & $0.74 \pm 0.12$ & $1.25 \pm 0.16$ & & \\
\hline oIPPV 0.8 L & $6.6 \pm 0.7$ & $0.89 \pm 0.07$ & $0.82 \pm 0.13$ & -3 & +5 \\
\hline oIPPV 1.2 L & $10.4 \pm 0.8$ & $1.22 \pm 0.27$ & $1.20 \pm 0.12$ & -1 & 0 \\
\hline
\end{tabular}

Values are mean \pm SEM. No change was significant. $P$ i: inspiratory pressure; $V_{\mathrm{rc}}$ : ribcage volume; $V$ ab: abdominal volume; $\Delta \mathrm{EEVrc:}$ change in end-expiratory ribcage volume; $\triangle E E V$ ab: change in end-expiratory abdominal volume; nIPPV: nasal intermittent positivepressure ventilation; oIPPV: oral intermittent positive-pressure ventilation. 

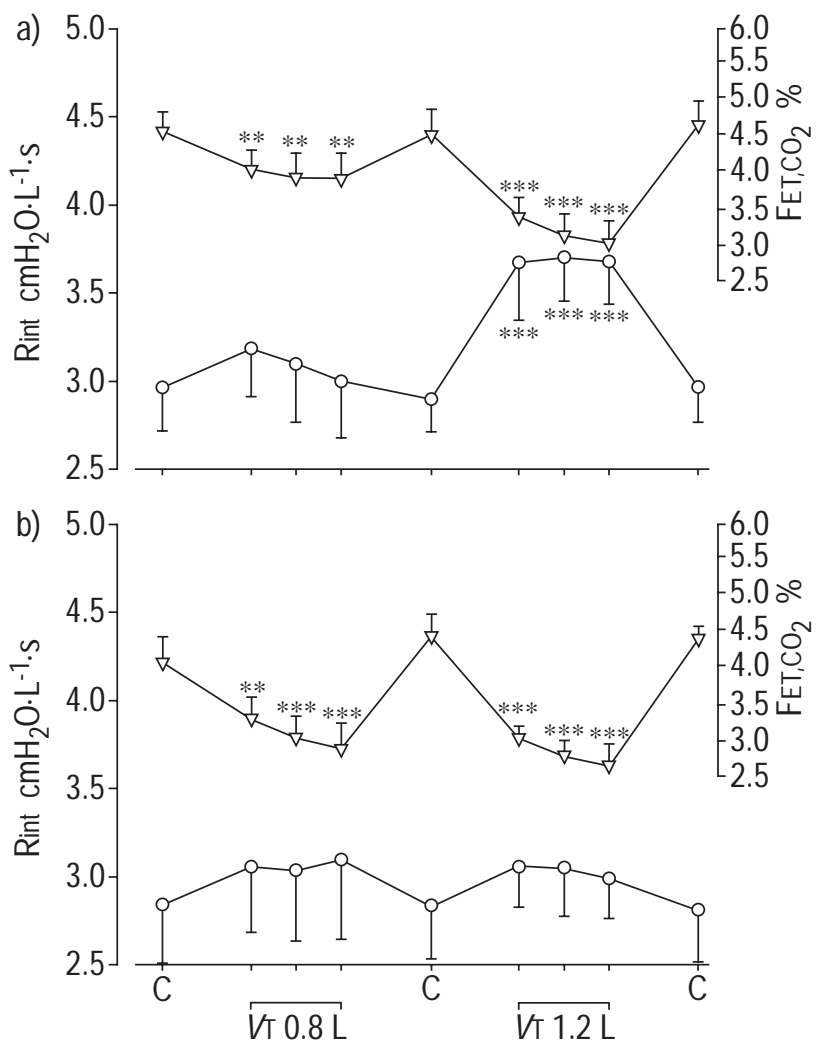

Fig. 1. - Interrupter resistance (Rint; $\bigcirc)$ measured during a) nasal or b) oral eupnoeic breathing of room air (C), then during 10-min periods of nasal intermittent positive-pressure ventilation (nIPPV; a) or oral intermittent positive-pressure ventilation (oIPPV; b) with a tidal volume $(V \mathrm{~T})$ at 0.8 or $1.2 \mathrm{~L}$, and after $10 \mathrm{~min}$ of spontaneous room air breathing $(\mathrm{C})$. Values are mean $\pm \operatorname{SEM}(\mathrm{n}=7) .{ }^{*}: \mathrm{p}<0.05 ; * *: \mathrm{p}<0.01 ; * * *: \mathrm{p}<0.001$, Rint values differing significantly from baseline values prior to nIPPV or oIPPV. $\nabla$ : end-tidal carbon dioxide fraction $\left(F \mathrm{ET}, \mathrm{CO}_{2}\right)$.

Rint response to $n I P P V$ or oIPPV. Control Rint values (table 1) were in the range of those measured by Phagoo et al. [16] during spontaneous breathing in humans (median: 2.4 , range: $1.0-3.5 \mathrm{cmH}_{2} \mathrm{O} \cdot \mathrm{L}^{-1} \cdot \mathrm{s}$ ). Figure 1 clearly shows that nIPPV significantly increased $R$ int value $(+22 \%)$ only when the $1.2 \mathrm{~L}$ stroke volume was used. The response plateaued throughout the 10-min period of nIPPV challenge. Rint changes were also found when the order of presentation of 0.8- and 1.2-L stroke volumes was inverted, as shown in figure 1, oIPPV did not induce any significant change in Rint, even though the fall in $F \mathrm{ET}, \mathrm{CO}_{2}$ was marked.

Rint response to nIPPV or oIPPV after adjustment of $\mathrm{FET}, \mathrm{CO}_{2}$ to its control level. Figure 2 shows that, after correction of nIPPV- or oPPV-induced falls in $\mathrm{FET}, \mathrm{CO}_{2}$ by adding pure $\mathrm{CO}_{2}$ into the inspiratory line, no significant $R$ int changes were measured.

Rint response to nIPPV after nose anaesthesia. Figure 3 clearly indicates that nose anaesthesia abolished the nIPPV-induced increase in Rint.

Rint response to nIPPV after oral inhalation of ipratropium bromide. Figure 3 shows that inhalation of a
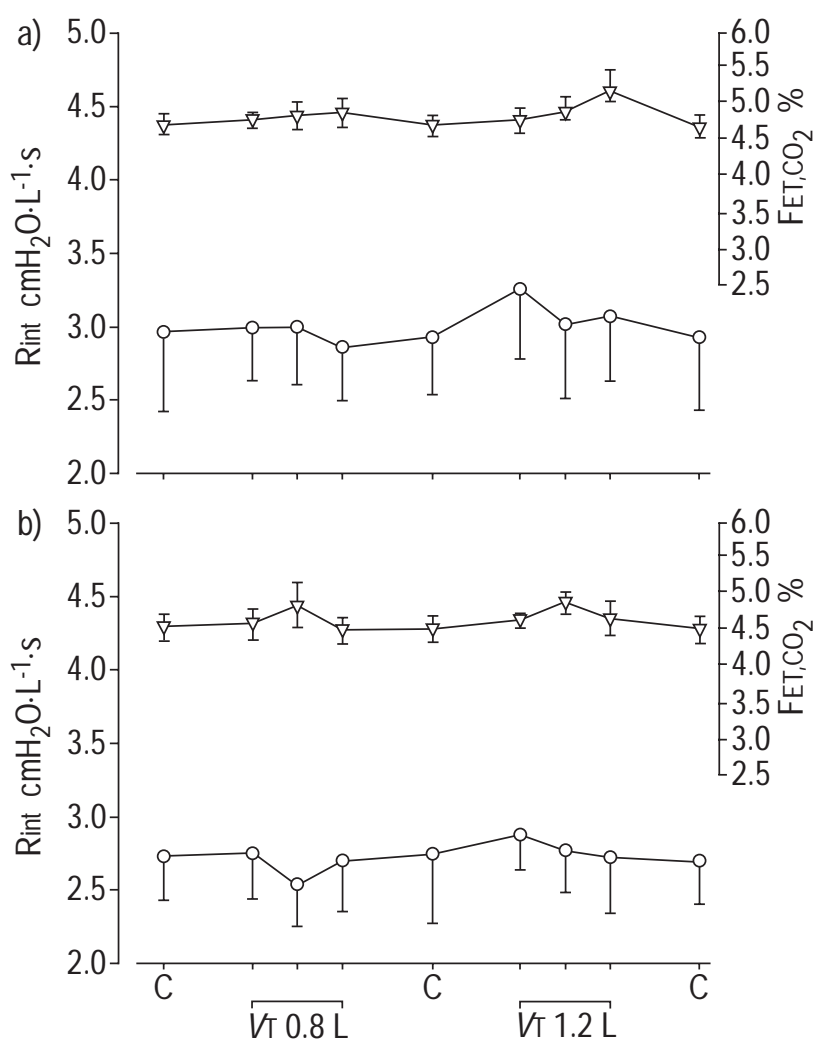

Fig. 2. - In five individuals, interrupter resistance (Rint; $\bigcirc)$ measurements were performed in the control $(C)$ condition then during nasal intermittent positive-pressure ventilation (nIPPV; a) or oral intermittent positive-pressure ventilation (oIPPV; b) as end-tidal carbon dioxide fraction $\left(F \mathrm{ET}, \mathrm{CO}_{2} ; \nabla\right)$ was maintained constant. Values are mean \pm SEM. $R$ int changes were never significant. $V \mathrm{~T}$ : tidal volume.

cholinergic antagonist abolished or markedly reduced the increase in Rint induced by nIPPV.

\section{Discussion}

The present study shows in normal subjects that nIPPV with a relatively high but commonly used stroke volume $\left(17 \mathrm{~mL} \cdot \mathrm{kg}^{-1}\right)$ induced a modest $(+22 \%)$ but significant and persistent increase in Rint. By contrast, Rint did not vary significantly during oIPPV, despite the fact that the reduction in expired $\mathrm{CO}_{2}$ concentration was even more accentuated in this situation compared to nIPPV. The response to nIPPV was abolished after correction of the associated hypocapnia. It also disappeared after local anaesthesia of the nose as well as after oral inhalation of a cholinergic antagonist.

These data indicate that the bronchoconstrictor response cannot be solely attributed to the fall in expired $\mathrm{CO}_{2}$ concentration, which is well-documented during hyperventilation $[19,20]$. Indeed, oIPPV elicited a marked fall in $F$ ET, $\mathrm{CO}_{2}$ but never increased the Rint values. Secondly, the nasal anaesthesia abolished the nIPPV-induced Rint changes, though hypocapnia was present in this experimental condition. In addition, the nIPPV-induced increase in Rint did not result from any vocal cord adduction because the response was abolished or markedly reduced by the cholinergic antagonist, a substance that did not affect the 

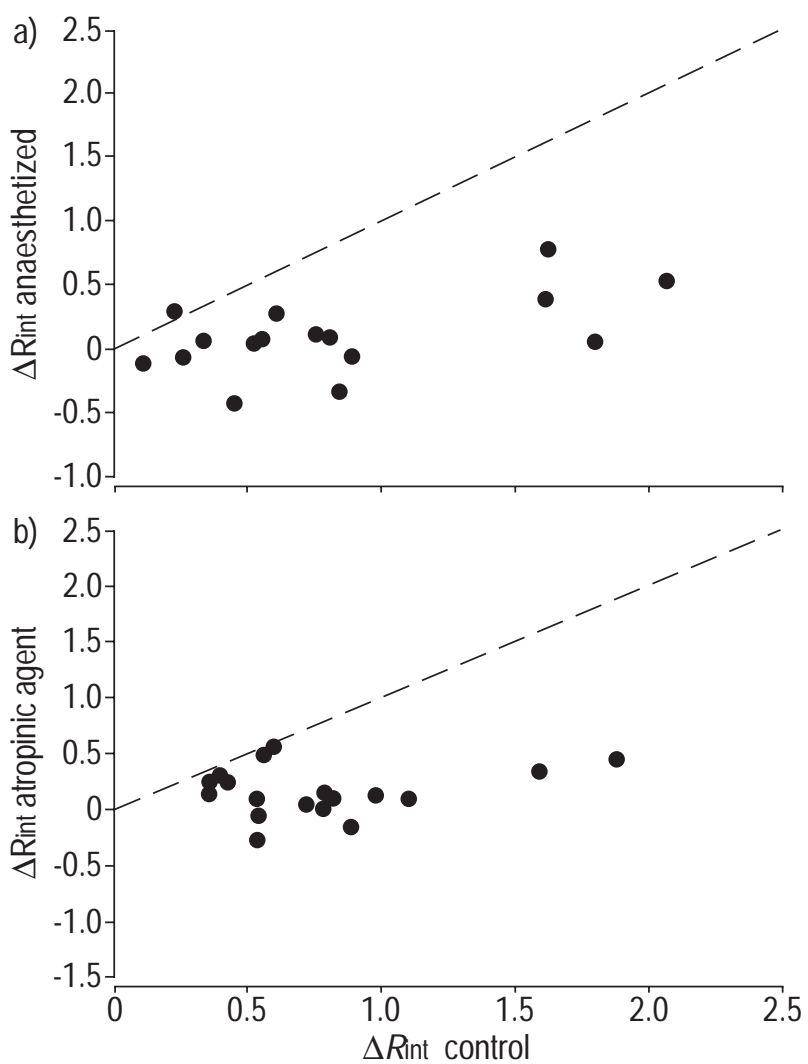

Fig. 3. - Change $(\Delta)$ in interrupter resistance (Rint) values during nasal intermittent positive-pressure ventilation (nIPPV) challenge in control condition versus $\Delta$ Rint values during nIPPV after a) nasal anaesthesia or b) inhalation of the cholinergic antagonist (atropinic agent). - - : identity lines.

striated laryngeal muscles. Thus, the nIPPV-induced Rint increase was attributed to a nasopulmonary bronchoconstrictor reflex, which seems to be potentiated by the associated fall in expired $\mathrm{CO}_{2}$ concentration.

In the literature, only one animal observation was found, which showed that hypercapnia attenuated the response of nasal trigeminal cold receptors [21]. TsuBONE [3] observed in rats that trigeminal thermoreceptors, which are markedly activated by cold air in the temperature range $0-15^{\circ} \mathrm{C}$, also operate as flow receptors. Although the effects of hypocapnia on the trigeminal afferents are not documented, it is tempting to speculate that hypocapnia may exert reverse effects from those of hypercapnia and potentiate the response of nasal flow-sensitive endings to mechanical stimulation. The present observation that the nIPPV-induced Rint increase persisted for four breaths (the 16-s period needed for two successive interruptions) after the subject was disconnected from the ventilator, favours the existence of residual changes in the $\mathrm{CO}_{2}$ content in the nasal mucosa.

Another explanation for the reflex bronchomotor response to nIPPV may be the activation of cold and/or osmoreceptors in the nose. Indeed, increasing the air flow stream through the nose, a condition realized during 1.2-L nIPPV trials, accentuates both the convective heat loss and the water loss in the nasal mucosa. In fact, during oIPPV, the subjects in the present study sometimes reported the sensation of cold or fresh air breathing during nIPPV and also of drying of the oropharyngeal cavity. However, cooling or drying the nasal mucosa in healthy subjects as well as in asthmatic patients $[6,7]$ elicited a reflex bronchospasm, irrespective of the expired $\mathrm{CO}_{2}$ concentration. Thus, the present observation of the nIPPV-induced $R$ int increase may not simply result from the stimulation of nose receptors detecting the changes in respiratory heat loss.

These results clearly showed that the airway response to nose stimulation involved the constriction of the airway smooth muscle and not the sole activation of adductor laryngeal muscles, as reported by JounIEAux et al. [13, 14]. This corroborates other results obtained in laryngectomized patients by Nolte and Berger [22], who found a nasopulmonary bronchoconstrictor reflex in response to cold stimulus (freon) applied to the nasal mucosa. The same response was found in one animal study on tracheotomized cats, which established that nose stimulation by irritants (direct touching, chemicals) elicited an increase in Raw [2].

The present data suggest that this method of mechanical ventilation, often used in patients with neuromuscular diseases, and sometimes in subjects presenting with a sleep apnoea syndrome, may alter pulmonary mechanics. It is suspect that a modest increase in ventilatory loading during nasal intermittent positive-pressure ventilation with a high stroke volume, instead of the reduced mechanical load, which is supposed to exist during assisted ventilation, may be the cause. It must be underlined that the present data were obtained in healthy subjects, and thus, the authors' have no idea of the magnitude of this nasopulmonary reflex in subjects suffering from asthma or rhinitis.

\section{References}

1. Lucier GE, Egizii R. Characterization of cat nasal afferents and brain stem neurones receiving ethmoidal input. Exp Neurol 1989; 103: 83-89.

2. Tomori Z, Widdicombe JG. Muscular, bronchomotor and cardiovascular reflexes elicited by mechanical stimulation of the respiratory tract. J Physiol (London) 1969; 200: 2549.

3. Tsubone H. Nasal 'flow' receptors of the rat. Respir Physiol 1989; 75: 51-64.

4. Ueki S, Domino EF. Some evidence for a mechanical receptor in olfactory function. $J$ Neurophysiol 1961; 24: $12-25$.

5. Wallois F, Macron JM, Jounieaux V, Duron B. Trigeminal nasal receptors related to respiration and to various stimuli in cats. Respir Physiol 1991; 85: 111-125.

6. Fontanari P, Burnet H, Zattara-Hartman MC, Jammes Y. Changes in airway resistance induced by nasal inhalation of cold dry, dry or moist air in normal individuals. $J$ Appl Physiol 1996; 81(4): 1739-1743.

7. Fontanari P, Zattara-Hartman MC, Burnet H, Jammes Y. Nasal eupneic inhalation of cold, dry air increases airway resistance in asthmatic patients. Eur Respir J 1997; 10: 2250-2254.

8. Kaufman J, Wright GW. The effect of nasal and nasopharyngeal irritation on airway resistance in man. Am Rev Respir Dis 1969; 100: 626-630.

9. Kaufman J, Chen JC, Wright GW. The effect of trigeminal resection on reflex bronchoconstriction after nasal and nasopharyngeal irritation in man. Am Rev Respir Dis 1970; 101: 768-769. 
10. Ishizuka Y, Usui N. Temporal change in the airway resistance following stimulation of the nasal mucosa. Auris Nasus Larynx (Tokyo) 1980; 7: 141-149.

11. Ellis ER, Bye PTP, Bruderer JW, Sullivan CE. Treatment of respiratory failure during sleep in patients with neuromuscular disease (positive-pressure ventilation through a nose mask). Am Rev Respir Dis 1987; 135: 148-152.

12. Strohl KP, Redline S. Nasal CPAP therapy, upper airway muscle activation, and obstructive sleep apnea. Am Rev Respir Dis 1986; 134: 555-558.

13. Jounieaux V, Aubert G, Dury M, Delguste P, Rodenstein DO. Effects of nasal positive-pressure hyperventilation on the glottis in normal awake subjects. J Appl Physiol 1995; 79(1): 176-185.

14. Jounieaux V, Aubert G, Dury M, Delguste P, Rodenstein DO. Effects of nasal positive-pressure hyperventilation on the glottis in normal sleeping subjects. $J$ Appl Physiol 1995; 79(1): 186-193.

15. Dubois AB, Botelho SW, Comroe JH. A new method for measuring airway resistance in man using a body plethysmograph. Values in normal subjects and in patients with respiratory disease. J Clin Invest 1956; 35: 327-334.
16. Phagoo SB, Watson RA, Silverman M, Pride NB. Comparison of four methods of assessing airflow resistance before and after induced airway narrowing in normal subjects. J Appl Physiol 1995; 79: 518-525.

17. D'Angelo E, Calderini E, Torri G, Robatto FM, Bono D, Milic-Emili J. Respiratory mechanics in anesthetized paralyzed humans: effects of flow, volume and time. $J \mathrm{Appl}$ Physiol 1989; 67: 2556-2564.

18. D'Angelo E, Robatto FM, Calderini E, et al. Pulmonary and chest wall mechanics in anesthetized paralyzed humans. J Appl Physiol 1991; 70: 2602-2610.

19. Newhouse MT, Becklake MR, Macklem PT, MacGregor M. Effects of alterations in end-tidal $\mathrm{CO}_{2}$ tension on flow resistance. J Appl Physiol 1964; 19: 745-749.

20. Sterling GM. The mechanism of bronchoconstriction due to hypocapnia in man. Clin Soc 1968; 34: 277-285.

21. Glebovsky VD, Bayev AV. Depressing effect of carbon dioxide on excitation of nasal cavity cold receptors in cats. Sechenov Physiol J USSR 1986; 72: 595-602.

22. Nolte D, Berger D. On vagal bronchoconstriction in asthmatic patients by nasal irritation. Eur J Respir Dis 1983; 64: $110-114$. 